\title{
Electroconvulsive therapy treatment in patients with somatic symptom and related disorders
}

\author{
This article was published in the following Dove Press journal: \\ Neuropsychiatric Disease and Treatment \\ 6 October 2015 \\ Number of times this article has been viewed
}

\author{
KaWai Leong' \\ Joseph CW Tham² \\ Anton Scamvougeras ${ }^{2}$ \\ Fidel Vila-Rodriguez ${ }^{3}$ \\ 'Department of Psychiatry, \\ ${ }^{2} \mathrm{BC}$ Neuropsychiatry Program, \\ Department of Psychiatry, ${ }^{3} \mathrm{Non}$ - \\ Invasive Neurostimulation Therapies \\ Laboratory at UBC, Department \\ of Psychiatry, University of British \\ Columbia, Vancouver, BC, Canada
}

\begin{abstract}
Objective: Medically unexplained somatic complaints are highly prevalent, and lead to significant impairment and disability. The number of effective treatment modalities for somatic symptom and related disorders (SSDs) or somatoform disorders (SDs) remains limited. To date, there is no formal indication for electroconvulsive therapy (ECT) in SSD or SD. We report on the largest case series to date regarding the effectiveness of ECT in patients with SSD and SD.

Methods: A retrospective chart review of all patients treated with an index course of ECT at the Neuropsychiatric Program at the University of British Columbia Hospital from 2000 to 2010 was conducted. The primary outcomes consisted of changes in pseudoneurologic symptoms, pain symptoms, cardiopulmonary symptoms, and gastrointestinal symptoms. Complaints were examined pre- and post-ECT.

Results: Twenty-eight participants were included in this study. Twenty-one participants received right unilateral ECT. Six received bifrontal ECT. One received bitemporal ECT. Eighteen of 21 participants reported improvement in pseudoneurologic symptoms; eleven of 14 participants reported improvement in pain symptoms; one participant reported improvement in cardiopulmonary symptoms; and one of two participants reported improvement in gastrointestinal symptoms. This paper discusses the putative mechanism of action of ECT in the treatment of SD/SSD.

Conclusion: This retrospective study suggests that ECT could be included as part of the existing treatment for refractory SSD and SD, particularly in refractory cases with comorbid mood disorders.
\end{abstract}

Keywords: electroconvulsive therapy, somatic symptoms, somatoform disorders

\section{Background}

Somatic symptom and related disorder (SSD), as defined in DSM-5, is characterized by somatic symptoms that are either very distressing or result in significant disruption of functioning. They could lead to excessive and disproportionate thoughts, feelings, and behaviors in relation to those symptoms. To be diagnosed with SSD, the individual must be persistently symptomatic. Two important clinical implications of the changes from DSM-IV-TR to DSM-5 are 1) hypochondriasis and body dysmorphic disorder are no longer considered as part of the SSD and 2) medically unexplained symptomatology is no longer required to make a diagnosis of SSD. This second aspect reflects a change in the conceptualization of SSD, that the interplay between medical conditions and psychiatric symptoms is a continuum with coexistence of medical and psychiatric features rather than a mind-body dichotomy. ${ }^{1}$

Since DSM-5 was only recently introduced, most published reports have utilized the older DSM-IV-TR framework. Epidemiological studies on somatoform disorders (SDs) have shown that the prevalence of medically unexplained somatic complaints in primary care settings is very high. ${ }^{2,3}$ These symptoms cause significant impairment
Correspondence: Fidel Vila-Rodriguez Non-Invasive Neurostimulation Therapies Laboratory at UBC (NINET), Department of Psychiatry, Faculty of Medicine, University of British Columbia, Detwiller Pavilion, 2255 Wesbrook Mall, Vancouver, BC V6T 2AI, Canada

Tel +I 6048270175

Email fidelvil@mail.ubc.ca
Neuropsychiatric Disease and Treatment 20I5:II 2565-2572 (c) (i) (5) 2015 Leong et al. This work is published by Dove Medical Press Limited, and licensed under Creative Commons Attribution - Non Commercial (unported, v3.0) License. The full terms of the License are available at http://creativecommons.org/licenses/by-nc/3.0/. Non-commercial uses of the work are permitted without any further permission from Dove Medical Press Limited, provided the work is properly attributed. Permissions beyond the scope of the License are administered by Dove Medical Press Limited. Information on
how to request permission may be found at: http://www.dovepress.com/permissions.php 
and disability, and management of these patients represents an enormous cost to the health care system. ${ }^{4-6}$ Furthermore, SDs are often comorbid with psychiatric disorders such as depression and anxiety. ${ }^{7,8}$ Specifically, a previous epidemiological study in the general population demonstrated that up to $22 \%$ of the patients with somatization disorder or pain disorder (PD) had at least one comorbid psychiatric diagnosis including mood disorders. ${ }^{9}$ Finally, studies in the primary care settings have shown a "dose-response" relationship between the number of physical symptoms and prevalence of mood and anxiety disorders. Comorbid anxiety or mood disorders occur in $44 \%-60 \%$ of patients who suffered from six or more physical symptoms independent of geographical or economic factors. ${ }^{10,11}$

With regard to management, SSDs are amenable to numerous strategies including cognitive behavioral therapy and pharmacotherapy. ${ }^{1,12,13}$ Prognosis tends to be more favorable when a model of stepped and shared care is used. ${ }^{14}$ However, in the most severe, treatment-refractory cases, even when multidisciplinary care is combined with complex augmentation and pharmacological therapies, prognosis often remains guarded. ${ }^{15}$

In severe treatment-refractory $\mathrm{SD}$, the use of electroconvulsive therapy (ECT) is increasingly being recognized as an effective treatment modality. ECT is a noninvasive convulsive neurostimulation treatment. With modified ECT, a brief, controlled generalized seizure is elicited by means of an electrical current applied to the patient's scalp while under general anesthesia. A wealth of evidence supports the use of ECT in many psychiatric conditions such as major depressive disorder (MDD), bipolar disorder, schizoaffective disorder, and schizophrenia. ${ }^{16}$ In fact, it is the most effective treatment for depression, with close to $80 \%$ response and remission rates. ${ }^{16}$ In treatment-refractory depression, the response rates following ECT are close to $60 \%$ and were found to be significantly higher than pharmacotherapy. ${ }^{17}$ Moreover, there are clinical situations where ECT is considered first-line treatment (eg, severe catatonic state, severe acute suicidality). ${ }^{18}$ However, the use of ECT is often limited by temporary cognitive side effects such as anterograde and short-term retrograde amnesia.

The overlap in etiopathogenesis combined with the epidemiological evidence showing a high degree of comorbidity between SDD and MDD have led clinicians to consider the use of ECT in SSD, and particularly in its most severe and refractory presentations. Indeed, there are case reports on the use of ECT with good outcomes in conversion disorder (CD), ${ }^{19-22}$ in somatization disorder and SD not otherwise specified, ${ }^{23,24}$ and in PD. ${ }^{24-40}$ Even though these case reports suggest positive outcomes using ECT for SSD, it is important to highlight several limitations including low number of cases and patient heterogeneity.

In the current study, we attempted to examine the extent to which ECT was effective in the treatment of SSD using a large case series of patients with SD treated with ECT. In addition, we examined the extent to which patients with the following groups of symptoms responded to an index regimen of ECT: pseudoneurological symptoms, pain symptoms, cardiopulmonary symptoms, and gastrointestinal (GI) symptoms. We hypothesized that ECT would be effective in these groups of symptoms, as suggested by previous case reports on $\mathrm{SD}$.

\section{Patients and methods}

A retrospective chart review of all patients treated with an index course of ECT, at the BC Neuropsychiatry Program at the University of British Columbia Hospital from 2000 to 2010 was performed. This tertiary subspecialty program has an outpatient department and a ten-bed inpatient unit for the assessment and treatment of complex neuropsychiatric cases including medically unexplained conditions in the province of British Columbia, Canada.

For this study, all patients admitted to the neuropsychiatry inpatient ward receiving ECT from 2000 to 2010 were reviewed. Cases were selected based on the clear DSMIV-TR diagnosis of SD as the main reason for admission and treatment and where ECT was specifically initiated with SD being the primary target of treatment.

Baseline information was collected and included the following: demographics (age, sex), DSM-IV-TR diagnoses, age of onset of the SD, duration of illness, number of medication trials before starting ECT, ECT parameters (placement of electrodes, stimulus parameters, anesthetic agent used for ECT), and outcome of ECT course (clinical change and adverse effects). Electrode placement (ie, right unilateral [RUL], bifrontal [BF], or bitemporal [BT]) was noted including the starting placement and any subsequent adjustments. During the decade from 2000 to 2010, all patients at the UBC Hospital were treated with the Thymatron System IV ECT machine by Somatics, Inc., set at $0.5 \mathrm{~ms}$ (brief) stimulus pulse width. Seizure duration was monitored using the electroencephalogram strip of bilateral frontopolar electrical activity.

In this study, the main outcome measure consisted of the participants' subjective change in clinical symptoms throughout the course of ECT (ie, pseudoneurologic, pain, 
cardiopulmonary, and GI symptoms). Each subject was assessed clinically by his/her assigned psychiatrist at least thrice weekly. These physiological systems were chosen to reflect commonly associated complaints in SSD and SD, independent of the changes from the DSM-IV-TR to DSM-5 criteria. When available, the depression outcome measures, such as Beck Depression Inventory (BDI) and Geriatric Depression Scale (GDS), were used to capture the change in depressive symptoms pre- and post-ECT treatment.

Ethical approval was obtained from the University of British Columbia Human Research Ethics Board and from the Vancouver Costal Health Research Institute. Patient consent was not required as no personal identifiers are mentioned.

\section{Results}

\section{Demographics and clinical characteristics}

In this case series, 28 participants (16 females and 12 males) who suffered from SD were treated with an index course of ECT (Table 1). Mean age of all participants was 48.7 years, and standard deviation (StDev) was 12 years.

\section{Table I Demographics}

\begin{tabular}{|c|c|}
\hline Number of patients (n) & 28 \\
\hline Female/male & $16 / 12$ \\
\hline Age (years; mean, StDev, range) & $48.7,12.0,19-74$ \\
\hline Female & $43.8,11.8,19-65$ \\
\hline \multirow[t]{2}{*}{ Male } & $54.8,9.79,4 I-75$ \\
\hline & $t$-test $(2.63, d f=26, P=0.014)$ \\
\hline \multicolumn{2}{|l|}{ Employment status } \\
\hline Unemployment rate & $100 \%$ (3 missing data) \\
\hline $\begin{array}{l}\text { Length of unemployment (years; } \\
\text { mean, StDev) }\end{array}$ & $6.05(4.77)$ \\
\hline \multicolumn{2}{|l|}{ Primary somatoform disorder diagnosis } \\
\hline Conversion disorder & 14 \\
\hline Pain disorder & 3 \\
\hline $\begin{array}{l}\text { Comorbid conversion disorder/pain } \\
\text { disorder }\end{array}$ & 9 \\
\hline Somatoform disorder NOS & 2 \\
\hline Comorbid psychiatric diagnoses & See Supplementary materials \\
\hline Age at onset (years; mean, StDev, range) & $39,11,16-57$ \\
\hline $\begin{array}{l}\text { Duration of illness (years; mean, StDev, } \\
\text { range) }\end{array}$ & $9,7,1-28$ \\
\hline $\begin{array}{l}\text { Number of med trials before ECT } \\
\text { (mean, StDev) }\end{array}$ & See Supplementary materials \\
\hline Antidepressants (mean, StDev) & $2.89,0.89$ \\
\hline Antipsychotics (mean, StDev) & $2.1,0.99$ \\
\hline $\begin{array}{l}\text { Number of health care professionals } \\
\text { involved in care }\end{array}$ & See Supplementary materials \\
\hline Number of medical comorbidities & See Supplementary materials \\
\hline \multicolumn{2}{|l|}{ Admission status } \\
\hline Voluntary & 20 (4 missing data) \\
\hline
\end{tabular}

Abbreviations: NOS, not otherwise specified; StDev, standard deviation; ECT, electroconvulsive therapy.
The mean length of unemployment secondary to SD was 6.05 years (StDev 4.77 years) based on data from 25 patients, and detailed data were unavailable for three patients. The unemployment rate prior to ECT treatment was $100 \%$. The mean, StDev, and range for the number of nonpsychiatric specialists consulted for their physical complaint(s) seen prior to ECT were 6.2, 3.3, and 0-13, respectively.

Among all participants, using the coded DSM-IV-TR diagnosis recorded in the charts at the time of admission, 14 participants suffered from CD, three suffered from PD, nine had comorbid pain and CD, and two had SD not otherwise specified. The mean duration, StDev, and range of length of illness prior to ECT were 9 years, 7 years, and 1-28 years, respectively. The mean number of psychiatric comorbidities (SD) was 2.5 (1.2). The mean, StDev, and range for the number of medical comorbidities were $4.39,3.33$, and $0-11$, respectively. The mean number of antidepressant trials prior to starting ECT was 2.89 (StDev 0.89 ), and the mean number of antipsychotics trials prior to starting ECT was 2.1 (StDev 0.99). Due to the physical complaints, the average number of medications other than psychotropics (antidepressant, mood stabilizers, benzodiazepine, and antipsychotics) being taken was 2.29 (StDev 1.8).

\section{ECT parameters and results}

Twenty-one participants began the study with RUL electrode placement (Tables 2 and 3). Among the participants beginning with unilateral placement, 14 of 21 participants $(67 \%)$ were subsequently switched to bilateral placement due to

Table 2 ECT parameters summary

\begin{tabular}{ll}
\hline $\begin{array}{l}\text { Number of treatments (mean, } \\
\text { range) }\end{array}$ & II.5, 3-22 \\
Initial electrode placement ( $\mathrm{n})$ & \\
$\quad$ RUL (switch) & $2 \mathrm{I}$ (I4 subsequently switched to BF) \\
BF & 6 \\
BT & $\mathrm{I}$ \\
Energy (Joule; mean, StDev) & 48.7 (I5.I) (missing data from one \\
& participant) \\
Pulse width (fixed) & 0.5 ms \\
Seizure duration (seconds; & 34.1 (II.6) \\
mean, StDev) & \\
Anesthetic agents used & \\
$\quad$ Sodium thiopental & 24 \\
Propofol & 2 \\
Methohexital & 2 \\
Succinylcholine & 28 \\
\hline
\end{tabular}

Abbreviations: $\mathrm{ECT}$, electroconvulsive therapy; RUL, right unilateral; BF, bifrontal; $\mathrm{BT}$, bitemporal; StDev, standard deviation. 


\section{Table 3 ECT results}

\begin{tabular}{ll}
\hline Immediate outcome (I month) (n) & \\
Improved & 22 \\
Unchanged & 4 \\
Worsened & 2 \\
Subsequent ECT course outcome (n) & II (all responded) \\
Improved & $3^{\text {a }}$ (2 responded) \\
Unchanged & $90,25-274$ \\
Duration of index admission in days (mean, range) \\
Reasons for ECT discontinuation (n) \\
$\quad$ Side effects & 6 \\
Lack of efficacy & 5 \\
\hline
\end{tabular}

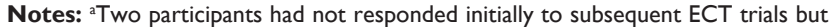
improved after more courses of ECT. Symptoms from one of these two participants went in remission with more courses of ECT.

Abbreviation: ECT, electroconvulsive therapy.

insufficient clinical response. Six participants were initiated with BF ECT, and one participant was started with BT ECT. The median number of ECT treatments was 11.5, with a range of 3-22 sessions across all participants.

\section{Pseudoneurologic symptoms}

Of 28 participants, $21(75 \%)$ reported pseudoneurologic symptoms including gait disturbance, nonepileptiform seizures, poor balance, muscle weakness, paresthesia, decreased vision, and abnormal movement (Table 4). Mean age for this subgroup was 49 years and StDev 12.4 years. Mean duration of symptoms in this subgroup of participants was 9 years and StDev 6.3 years. Among the 21 participants in this subgroup, all had a comorbid MDD. Other comorbidities included dysthymic disorder $(n=1)$, generalized anxiety disorder $(\mathrm{n}=1)$, panic disorder $(\mathrm{n}=1)$, adjustment disorder $(n=1)$, posttraumatic stress disorder (PTSD) $(n=7)$, psychotic symptoms $(\mathrm{n}=5)$, obsessive-compulsive disorder $(n=1)$, obsessive-compulsive personality disorder $(n=1)$,

Table 4 Most reported pseudoneurological symptoms

\begin{tabular}{ll}
\hline Pseudoneurological symptoms & Frequency \\
\hline Pain & 15 \\
Extremities weakness & 11 \\
Balance/gait disturbance & 8 \\
Incontinence & 6 \\
Paresthesia & 6 \\
Pseudoseizure & 6 \\
Cognitive dysfunction & 4 \\
Involuntary movement & 4 \\
Aphasia & 3 \\
Tremor & 3 \\
Vision disturbance & 2 \\
Vertigo & 2 \\
Coordination & 1 \\
Dyskinesia & 1 \\
Mutism & 1 \\
\hline
\end{tabular}

borderline personality disorder $(n=1)$, specific phobia $(n=1)$, and comorbid substance abuse $(\mathrm{n}=1)$. The mean number of ECT treatments for this subgroup was 11.7 sessions, StDev 4.6 sessions, and range 3-22 sessions. With respect to the electrode placement, nine participants had RUL placement for the majority of their ECT regimen. Ten participants had BF placement. One participant had BT placement. One participant had six RUL and six BF sessions in his ECT regimen. Switch in the electrode placement occurred in nine participants in this subgroup. Seven of 21 (33\%) patients with pseudoneurologic symptoms discontinued ECT earlier than the number ordered on the charts. The documented reasons and their frequencies were as follows: confusion $(n=1)$, side effects related to ECT $(\mathrm{n}=2)$, worsening of symptoms $(n=2)$, lack of efficacy $(n=1)$, and nonspecific $(n=2)$.

\section{Pain symptoms}

Pain symptoms included the following: headache, jaw and facial pain, chest pain, pain in extremities, back pain, and pancorporeal pain. Mean age for this subgroup was 52.4 years and StDev 10.6 years. Mean duration of symptoms in this subgroup of participants was 8.2 years and StDev 5.3 years. Among the 14 participants in this subgroup, all had a comorbid MDD. Other comorbidities included adjustment disorder $(\mathrm{n}=1)$, PTSD $(\mathrm{n}=5)$, attention-deficit hyperactivity disorder $(n=1)$, psychotic symptoms ( $n=5)$, specific phobia $(n=2)$, and substance abuse $(n=1)$. The mean number of ECT for this subgroup was 12.2 sessions, StDev 4.7 sessions, and range 4-21 sessions. With respect to the electrode placement, ten participants had RUL placement for the major part of their ECT regimen. Four participants had BF placement. Switch in the electrode placement occurred in eight participants (57\%) in this subgroup. Four of 14 patients with pain symptoms discontinued ECT prematurely. The stated reasons and their frequencies were as follows: confusion $(\mathrm{n}=1)$, side effects related to anesthetic induction or recovery $(n=1)$, and worsening of symptoms $(n=1)$; one patient described both side effects related to anesthetic induction and worsening of her symptoms.

\section{Cardiopulmonary symptoms}

One participant reported significant shortness of breath in addition to extremity pain and urinary incontinence. He was 62 years old and had the above-mentioned symptoms for close to 10 years. In terms of psychiatric comorbidities, he had comorbid MDD, anxiety, and psychotic symptoms. In terms of medical history, he had no cardiovascular risk factors but had a history of pulmonary sarcoidosis (in remission 
at the time of treatment). This patient received eleven ECT sessions (six RUL and five BF).

\section{Gl symptoms}

Two participants reported significant GI symptoms in addition to extremity weakness. The GI symptoms shared many similarities with irritable bowel syndrome (abdominal cramping, bloating, diarrhea, or constipation often related to environmental stressors). Mean age for this subgroup was 49.8 years and StDev 0.5 year. Mean duration of symptoms in this subgroup of participants was 18.3 years and StDev 14 years. Among the two patients in this subgroup, both had a comorbid MDD. One patient had comorbid generalized anxiety disorder, obsessivecompulsive disorder, and possible sleep and eating disorders. The other patient had comorbid specific phobia. With respect to past medical history, one had diabetes mellitus type 2, dyslipidemia, and a history of mild traumatic brain injury secondary to a remote motor vehicle accident. The other patient had a history of remote viral encephalitis.

Both patients had ten ECT sessions. With respect to the electrode placement, one participant had RUL placement for the full ECT regimen. The other participant had BF electrode placement for the full course.

\section{Clinical outcomes}

Eighteen of 21 patients (86\%) with pseudoneurologic symptoms reported subjective significant improvement. Two patients in this group reported no significant changes and one patient reported subjective deterioration of her symptoms following ECT.

Eleven of 14 patients (79\%) with pain symptoms reported significant subjective improvement by the end of the index course. Three patients (21\%) in this group reported subjective worsening of their pain following ECT.

The only patient with cardiopulmonary symptoms reported moderate improvements in his mood, pain, and cardiopulmonary symptoms.
Of two patients with GI symptoms, one patient discontinued ECT prematurely due to lack of clinical efficacy and one patient reported significant improvement in GI symptoms.

In terms of mood symptoms, many of our participants reported subjective improvement. In three participants, subjects 2,3 , and 5 , we captured changes in mood symptoms using the self-reported GDS, which revealed $-6,-12$, and +2 , respectively, pre- and post-ECT treatment. In the other three participants, subjects 8,18 , and 20 , we captured changes in mood symptoms using the BDI, which revealed $-14,-20$, and -5 points, respectively.

In total, 22 of 28 patients were assessed to have shown significant improvement with regard to their SD/SSD-related physical symptoms after an index course of ECT. Table 5 summarized the characteristics of the six nonresponders to ECT treatment for their somatic symptoms.

\section{Discussion}

At this time, we believe this is the largest case series published on SSD/SD treated with ECT. In this case series, we used a symptoms-based approach to examine the extent to which an index course of ECT led to clinical changes across four categories of symptoms: pseudoneurologic complaints, pain, cardiopulmonary, and GI symptoms. Several key observations can be made.

First, from the review of demographic information, the inability to work due to disability was high in the population of SD patients reported in this study. This speaks of the severity and functional disruption posed by this condition. Second, SD were not mutually exclusive. In fact, the clinical symptoms of 13 participants in this study would qualify for more than one SD using the DSM-IV-TR criteria used at the time when these patients were treated. Third, SD were highly comorbid with mood and anxiety disorders. In fact, all participants (100\%) had comorbid MDD. PTSD was comorbid in ten of the 28 (36\%) participants in this case series. Finally, 22 of 28 (79\%) patients in this case series reported significant

Table 5 Nonresponders characteristics

\begin{tabular}{lllllllll}
\hline Subject ID & Outcome & Sex & Age of onset & Dx $^{\text {a }}$ & Symptoms domain & ECT placement & Number of Rx & Subsequent ECT \\
\hline II & No change & F & 34 & CD & Pseud-Neu & RUL & 9 & Yes (remission) \\
I3 & No change & M & 50 & CD + Pain & Pseud-Neu/Pain & BF/RUL & 10 & No \\
16 & Worsened & M & 39 & CD & Pseud-Neu & BF & 14 & No \\
20 & No change & M & 22 & Som-NOS & Pain/GI & RUL & 10 & No \\
23 & Worsened & M & 51 & Pain & Pain & RUL/BF & 12 & No \\
28 & No change & F & 34 & CD & Pseud-Neu & RUL/BF & 6 & No \\
\hline
\end{tabular}

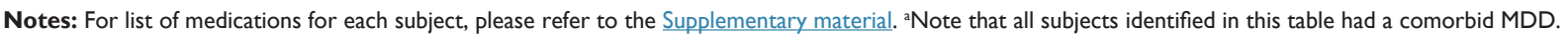
Abbreviations: BF, bifrontal placement; CD, conversion disorder; ECT, electroconvulsive therapy; F, female; GI, gastrointestinal symptoms; M, male; Pain, pain disorder; Pseud-Neu, pseudoneurological symptoms; RUL, right unilateral placement; Som-NOS, somatoform disorder not otherwise specified; MDD, major depressive disorder; Dx, diagnosis; Rx, prescription. 
improvement in their respective somatic symptoms after an index course of ECT.

Evidence suggests that SSD and SD are psychiatric disorders that could be caused by functional abnormalities of the central nervous system rather than being only "diseases of the mind". ${ }^{41}$ Studies have supported probable neurobiological underpinnings of somatoform symptoms. ${ }^{8,42-47}$ Recently, Dukart et $\mathrm{al}^{48}$ reported the potential for ECT to create long-term structural changes in the limbic system and in the prefrontal cortex. Similarly, several studies have shown that ECT may affect regional cerebral blood flows or cerebral metabolic rates. ${ }^{49-51}$ Whether the reported improvements in somatoform symptoms in the current study could be correlated with neurobiological changes post-ECT will require further investigations.

Although the precise mechanism of action of ECT remains unclear, converging lines of evidence point to the interaction between the neuroendocrine and immunologic systems modulated by ECT as a current hypothesis. Both MDD and SD/SSD have been suggested to share similar abnormalities in the neuroendocrine and immunologic systems. ${ }^{52}$ In patients with MDD, ECT has been shown to increase the level of brain-derived neurotrophic factor, often found to be at a decreased level in depression and tends to normalize when treated with antidepressant medications. ${ }^{53,54}$ In addition, electrically induced seizures in animal models have demonstrated an increase in neurogenesis and synaptic plasticity in the hippocampus ${ }^{55,56}$ and in the rostral-medial striatum. ${ }^{57}$ It is possible that these observed neurobiological changes could lead to improvement in monoamine neurotransmitters functioning. ${ }^{58}$ Ernst et $\mathrm{al}^{59}$ in a recent article, discussed the possibility that neurogenesis in the adult human brain could extend beyond the hippocampi to the striatum. As an important player of the limbic system, the striatum could play a significant role in emotion regulation in a multitude of psychiatric disorders. ${ }^{60}$ Hence, ECT could lead to improvement in psychiatric symptoms through optimization of neurogenesis and synaptic plasticity. Moreover, ECT was found to play a significant role in the modulation of the immunological system, including psychiatric illness. ${ }^{61,62}$ It is believed that the protracted effects of stressors and cytokines may play an important role in the pathophysiology of amplification of somatic complaints. ${ }^{63}$ Early evidence suggested that ECT could bring about a balance between inhibition and activation of the immunological system. For example, ECT was found to attenuate the proinflammatory state by inducing long-lasting changes in macrophage function in mice ${ }^{64}$ and to increase lymphocytic expression of activation antigens and natural killer cell activity. ${ }^{62}$ Furthermore, ECT has been shown to decrease the levels of tumor necrosis factor in severe depressive disorder, hence decreasing the level of proinflammatory molecules present in severe MDD ${ }^{65}$ Finally, ECT appears to decrease the levels of tumor necrosis factor in severe MDD, again decreasing the level of the proinflammatory state. ${ }^{65}$

In this report, the observed changes in SSD and SD symptoms post-ECT might be primarily related to the effect of adequate treatment of psychiatric comorbidities such as MDD. In fact, one of ECT's main indications is MDD. ${ }^{66}$ Hurwitz $^{67}$ described that the pathophysiology of conversion symptoms may begin with a psychiatric illness, most commonly depression, and that somatoform symptoms serve as "a somatic defense to govern behavior", thereby leading to nonorganic findings on clinical examination. Of note, somatic delusions are often encountered in severe MDD.$^{68}$ In this report, whether MDD preceded or followed the onset of important somatic symptoms remained unknown. As described earlier, substantial epidemiological studies have shown high rates of comorbidity between SSD and mood disorders. In this series, despite inconsistent objective measures used for the assessment of pre- and post-ECT levels of depression, a number of our participants showed improvement in the GDS and BDI.

When drawing conclusions from this case series, one should be mindful that this is a retrospective collection of case reports, with all the implied limitations. In addition, with the recent changes in the SSD DSM-5 diagnostic criteria, we decided to focus on describing the effects of ECT on various somatic systems rather than focus on the disorders as described in the DSM. Therefore, we cannot know if ECT would be beneficial for all disorders in this classification even though on the whole, the majority of patients appeared to have benefited from the treatment. In this report, medication adjustments and psychotherapeutic interventions were not controlled for during the ECT treatment, thus raising the possibility that symptomatic improvements may have been related to factors other than ECT. Furthermore, it is important to highlight that outcome measures were subjective and potentially open to bias. Yet, we share the results of the response to ECT of this group of individuals suffering severe, chronic, treatment-refractory somatic symptoms with comorbid depression in the belief that clinicians in the field attempting to help patients in similar situations may benefit from knowing that many such patients appeared to improve clinically with this modality of treatment. A prospective design with rigorous diagnostic consistency, controlling for medication and psychotherapeutic changes, and objective outcome measures would be needed to overcome these limitations. 


\section{Conclusion}

Although we cannot advise that ECT should be used broadly for the treatment of SSD based on this report, we believe this case series adds further support to the existing literature on the effectiveness of ECT. Based on the cases presented, the majority of patients with chronic refractory SSD with comorbid MDD benefited from the ECT treatment. We noted the improvement in both somatic features and affective symptoms.

\section{Disclosure}

The authors report no conflicts of interest in this work.

\section{References}

1. Mayou R. Are treatments for common mental disorders also effective for functional symptoms and disorder? Psychosom Med. 2007; 69(9):876-880.

2. Simon GE, Gureje O. Stability of somatization disorder and somatization symptoms among primary care patients. Arch Gen Psychiatry. 1999;56(1):90-95.

3. Kirmayer LJ, Robbins JM. Three forms of somatization in primary care: prevalence, co-occurrence, and sociodemographic characteristics. J Nerv Ment Dis. 1991;179(11):647-655.

4. Katon W, Lin E, Von Korff M, Russo J, Lipscomb P, Bush T. Somatization: a spectrum of severity. Am J Psychiatry. 1991;148(1):34-40.

5. Escobar JI, Golding JM, Hough RL, Karno M, Burnam MA, Wells KB. Somatization in the community: relationship to disability and use of services. Am J Public Health. 1987;77(7):837-840.

6. Reid S, Wessely S, Crayford T, Hotopf M. Frequent attenders with medically unexplained symptoms: service use and costs in secondary care. Br J Psychiatry. 2002;180:248-253.

7. Frohlich C, Jacobi F, Wittchen HU. DSM-IV pain disorder in the general population. An exploration of the structure and threshold of medically unexplained pain symptoms. Eur Arch Psychiatry Clin Neurosci. 2006;256(3):187-196.

8. Cojan Y, Waber L, Carruzzo A, Vuilleumier P. Motor inhibition in hysterical conversion paralysis. Neuroimage. 2009;47(3):1026-1037.

9. Jacobi F, Wittchen H-U, Holting C, et al. Prevalence, co-morbidity and correlates of mental disorders in the general population: results from the German Health Interview and Examination Survey (GHS). Psychol Med. 2004;34(4):597-611.

10. Kroenke K, Spitzer RL, Williams JB, et al. Physical symptoms in primary care. Predictors of psychiatric disorders and functional impairment. Arch Fam Med. 1994;3(9):774-779.

11. Simon G, Gater R, Kisely S, Piccinelli M. Somatic symptoms of distress: an international primary care study. Psychosom Med. 1996; 58(5):481-488.

12. Schroder A, Rehfeld E, Ornbol E, Sharpe M, Licht RW, Fink P. Cognitive-behavioural group treatment for a range of functional somatic syndromes: randomised trial. Br J Psychiatry. 2012;200(6):499-507.

13. Zonneveld LN, van Rood YR, Timman R, Kooiman CG, Van't Spijker A, Busschbach JJ. Effective group training for patients with unexplained physical symptoms: a randomized controlled trial with a non-randomized one-year follow-up. PLoS One. 2012;7(8):e42629.

14. van der Feltz-Cornelis CM, Hoedeman R, Keuter EJ, Swinkels JA. Presentation of the Multidisciplinary Guideline Medically Unexplained Physical Symptoms (MUPS) and Somatoform Disorder in the Netherlands: disease management according to risk profiles. JPsychosom Res. 2012;72(2):168-169.

15. Nagoshi Y, Tominaga T, Fukui K. Effect of aripiprazole augmentation for treatment-resistant somatoform disorder: a case series. J Clin Psychopharmacol. 2014;34(3):397-398.
16. Mankad MV, Beyer JL, Weiner RD, Krystal AD. Clinical Manual of Electroconvulsive Therapy. 2nd ed. Washington, DC: American Psychiatric Association; 2010.

17. Folkerts HW, Michael N, Tolle R, Schonauer K, Mucke S, SchulzeMonking H. Electroconvulsive therapy vs paroxetine in treatmentresistant depression - a randomized study. Acta Psychiatr Scand. 1997; 96(5):334-342.

18. Enns MW, Reiss JP, Chan P. Electroconvulsive therapy position paper. Can Psychiatr Assoc J. 2009;55(6):12.

19. Daniel WF, Yeo RA, Smith JE. Conversion disorders and ECT. BrJ Psychiatry. 1989;154:274-275.

20. Caplan JP, Binius T, Lennon VA, Pittock SJ, Rao MS. Pseudopseudoseizures: conditions that may mimic psychogenic non-epileptic seizures. Psychosomatics. 2011;52(6):501-506.

21. Blumer D, Rice S, Adamolekun B. Electroconvulsive treatment for nonepileptic seizure disorders. Epilepsy Behav. 2009;15(3):382-387.

22. Giovanoli EJ. ECT in a patient with conversion disorder. Convuls Ther. 1988;4(3):236-242.

23. Gahr M, Schonfeldt-Lecuona C, Connemann BJ. Somatization disorder treated with electroconvulsive therapy. J ECT. 2011;27(3):266-267.

24. McGirr A, Davis L, Vila-Rodriguez F. Idiopathic burning mouth syndrome: a common treatment-refractory somatoform condition responsive to ECT. Psychiatry Res. 2014;216(1):158-159.

25. Rasmussen KG, Rummans TA. Electroconvulsive therapy for phantom limb pain. Pain. 2000;85(1-2):297-299.

26. Fukui S, Shigemori S, Nosaka S. Changes in regional cerebral blood flow in the thalamus after electroconvulsive therapy for patients with complex regional pain syndrome type 1 (preliminary case series). Reg Anesth Pain Med. 2002;27(5):529-532.

27. Fukui S, Shigemori S, Yoshimura A, Nosaka S. Chronic pain with beneficial response to electroconvulsive therapy and regional cerebral blood flow changes assessed by single photon emission computed tomography. Reg Anesth Pain Med. 2002;27(2):211-213.

28. Rasmussen KG, Rummans TA. Electroconvulsive therapy in the management of chronic pain. Curr Pain Headache Rep. 2002;6(1):17-22.

29. Von Hagen KO. Chronic intolerable pain; discussion of its mechanism and report of eight cases treated with electroshock. J Am Med Assoc. 1957;165(7):773-777.

30. Bloomstein JR, Rummans TA, Maruta T, Lin SC, Pileggi TS. The use of electroconvulsive therapy in pain patients. Psychosomatics. 1996;37(4):374-379.

31. Mandel MR. Electroconvulsive therapy for chronic pain associated with depression. Am J Psychiatry. 1975;132(6):632-636.

32. Janjigian ER. Report of three cases of trigeminal neuralgia apparently cured by electroshock therapy. Am J Psychiatry. 1949;106(2):143.

33. Pisetsky JE. Disappearance of painful phantom limbs after electric shock treatment. Am J Psychiatry. 1946;102:599-601.

34. McDaniel WW. Electroconvulsive therapy in complex regional pain syndromes. J ECT. 2003;19(4):226-229.

35. Schreiber S, Shmueli D, Grunhaus L, et al. The influence of electroconvulsive therapy on pain threshold and pain tolerance in major depression patients before, during and after treatment. Eur J Pain. 2003;7(5):419-424.

36. Wolanin MW, Gulevski V, Schwartzman RJ. Treatment of CRPS with ECT. Pain Physician. 2007;10(4):573-578.

37. Hampf G, Kuoppasalmi K, Henriksson M, Achte K. Chronic facial pain together with severe depression is responsive to electroconvulsive therapy. A case report. Acta Odontol Scand. 1992;50(3):129-132.

38. Usui C, Doi N, Nishioka M, et al. Electroconvulsive therapy improves severe pain associated with fibromyalgia. Pain. 2006;121(3): 276-280.

39. Wasan AD, Artin K, Clark MR. A case-matching study of the analgesic properties of electroconvulsive therapy. Pain Med. 2004;5(1): $50-58$

40. King JH, Nuss S. Reflex sympathetic dystrophy treated by electroconvulsive therapy: intractable pain, depression, and bilateral electrode ECT. Pain. 1993;55(3):393-396. 
41. Sydenham T. The Works of Thomas Sydenham, MD. Vol 2. Sydenham Society; 1848; London, UK

42. Ghaffar O, Staines WR, Feinstein A. Unexplained neurologic symptoms: an fMRI study of sensory conversion disorder. Neurology. 2006;67(11):2036-2038.

43. Hurwitz TA, Prichard JW. Conversion disorder and fMRI. Neurology. 2006;67(11):1914-1915.

44. Mailis-Gagnon A, Giannoylis I, Downar J, et al. Altered central somatosensory processing in chronic pain patients with "hysterical" anesthesia. Neurology. 2003;60(9):1501-1507.

45. Marshall JC, Halligan PW, Fink GR, Wade DT, Frackowiak RS. The functional anatomy of a hysterical paralysis. Cognition. 1997;64(1): B1-B8.

46. Tiihonen J, Kuikka J, Viinamaki H, Lehtonen J, Partanen J. Altered cerebral blood flow during hysterical paresthesia. Biol Psychiatry. 1995; 37(2):134-135.

47. Vuilleumier P, Chicherio C, Assal F, Schwartz S, Slosman D, Landis T. Functional neuroanatomical correlates of hysterical sensorimotor loss. Brain. 2001;124(pt 6):1077-1090.

48. Dukart J, Regen F, Kherif F, et al. Electroconvulsive therapy-induced brain plasticity determines therapeutic outcome in mood disorders. Proc Natl Acad Sci U S A. 2014;111(3):1156-1161.

49. Sackeim HA. The anticonvulsant hypothesis of the mechanisms of action of ECT: current status. J ECT. 1999;15(1):5-26.

50. Nobler MS, Oquendo MA, Kegeles LS, et al. Decreased regional brain metabolism after ect. Am J Psychiatry. 2001;158(2):305-308.

51. Yatham LN, Clark CC, Zis AP. A preliminary study of the effects of electroconvulsive therapy on regional brain glucose metabolism in patients with major depression. $J E C T .2000 ; 16(2): 171-176$.

52. Irwin MR. Inflammation at the intersection of behavior and somatic symptoms. Psychiatr Clin North Am. 2011;34(3):605-620.

53. Bilgen AE, Bozkurt Zincir S, Zincir S, et al. Effects of electroconvulsive therapy on serum levels of brain-derived neurotrophic factor and nerve growth factor in treatment resistant major depression. Brain Res Bull. 2014; 104:82-87.

54. Sen S, Duman R, Sanacora G. Serum brain-derived neurotrophic factor, depression, and antidepressant medications: meta-analyses and implications. Biol Psychiatry. 2008;64(6):527-532.

55. Hellsten J, Wennstrom M, Mohapel P, Ekdahl CT, Bengzon J, Tingstrom A. Electroconvulsive seizures increase hippocampal neurogenesis after chronic corticosterone treatment. Eur J Neurosci. 2002;16(2):283-290.
56. Chen F, Madsen TM, Wegener G, Nyengaard JR. Repeated electroconvulsive seizures increase the total number of synapses in adult male rat hippocampus. Eur Neuropsychopharmacol. 2009;19(5):329-338.

57. Inta D, Lima-Ojeda JM, Lau T, et al. Electroconvulsive therapy induces neurogenesis in frontal rat brain areas. PLoS One. 2013;8(7):e69869.

58. Wahlund B, von Rosen D. ECT of major depressed patients in relation to biological and clinical variables: a brief overview. Neuropsychopharmacology. 2003;28(suppl 1):S21-S26.

59. Ernst A, Alkass K, Bernard S, et al. Neurogenesis in the striatum of the adult human brain. Cell. 2014;156(5):1072-1083.

60. McGeorge AJ, Faull RL. The organization of the projection from the cerebral cortex to the striatum in the rat. Neuroscience. 1989;29(3): 503-537.

61. Fluitman SB, Heijnen CJ, Denys DA, Nolen WA, Balk FJ, Westenberg HG. Electroconvulsive therapy has acute immunological and neuroendocrine effects in patients with major depressive disorder. $J$ Affect Disord. 2011;131(1-3):388-392.

62. Fischler B, Bocken R, Schneider I, De Waele M, Thielemans K, Derde MP. Immune changes induced by electroconvulsive therapy (ECT). Ann N Y Acad Sci. 1992;650:326-330.

63. Dimsdale JE, Dantzer R. A biological substrate for somatoform disorders: importance of pathophysiology. Psychosom Med. 2007;69(9): $850-854$.

64. Roman A, Nawrat D, Nalepa I. Chronic treatment with electroconvulsive shock may modulate the immune function of macrophages. $J E C T$. 2008;24(4):260-267.

65. Hestad KA, Tonseth S, Stoen CD, Ueland T, Aukrust P. Raised plasma levels of tumor necrosis factor alpha in patients with depression: normalization during electroconvulsive therapy. $J E C T$. 2003;19(4): $183-188$.

66. Kennedy SH, Milev R, Giacobbe P, et al; Canadian Network for Mood and Anxiety Treatments (CANMAT). Canadian Network for Mood and Anxiety Treatments (CANMAT) clinical guidelines for the management of major depressive disorder in adults. IV. Neurostimulation therapies. $J$ Affect Disord. 2009;117(suppl 1):S44-S53.

67. Hurwitz TA. Somatization and conversion disorder. Can J Psychiatry. 2004;49(3):172-178.

68. Kapfhammer HP. Somatic symptoms in depression. Dialogues Clin Neurosci. 2006;8(2):227-239.
Neuropsychiatric Disease and Treatment

\section{Publish your work in this journal}

Neuropsychiatric Disease and Treatment is an international, peerreviewed journal of clinical therapeutics and pharmacology focusing on concise rapid reporting of clinical or pre-clinical studies on a range of neuropsychiatric and neurological disorders. This journal is indexed on PubMed Central, the 'PsycINFO' database and CAS,

\section{Dovepress}

and is the official journal of The International Neuropsychiatric Association (INA). The manuscript management system is completely online and includes a very quick and fair peer-review system, which is all easy to use. Visit http://www.dovepress.com/testimonials.php to read real quotes from published authors. 